\title{
Amblyopia: is visual loss permanent?
}

\author{
Mai K El Mallah, Usha Chakravarthy, Patricia M Hart
}

\begin{abstract}
Aim-To ascertain whether recovery of visual function in amblyopic eyes is likely to occur when the fellow eye is lost as a result of age related macular degeneration.

Methods-The records of 465 patients with an established diagnosis of age related macular degeneration who had attended a specialist macular clinic between 1990 and 1998 were scrutinised. A full clinical examination and standardised refraction had been carried out in 189 of these cases on a minimum of two occasions. Cases were looked for where an improvement of one or more lines of either distance or near acuity was recorded in the eye unaffected by macular disease. In each one of these cases the improvement in visual acuity could not be attributed to treatment of other existing pathology.

Results-12 such cases were detected. In nine of these the eye showing improvement of acuity had a history of amblyopia. The mean improvement in distance and near acuity in amblyopic eyes by 12 months was 3.3 and 1.9 lines $\operatorname{logMAR}$ respectively. The improvement in acuity generally occurred between 1 and 12 months from baseline and remained stable over the period of follow up. Conclusions-Older people with a history of amblyopia who develop visual loss in the previously normal eye can experience recovery of visual function in the amblyopic eye over a period of time. This recovery in visual function occurs in the wake of visual loss in the fellow eye and the improvement appears to be sustained.
\end{abstract} (Br F Ophthalmol 2000;84:952-956)

Amblyopia is a reduction in visual acuity as a result of a developmental disorder of spatial vision arising from strabismus, anisometropia, or form deprivation early in life. ${ }^{12}$ The latter three conditions lead to insufficient exposure to sharply focused images and a difference in the quality of the inputs from the two eyes to the binocular visual centres of the brain. The brain then continually favours the eye with better vision to the eventual detriment of visual development in the other eye. The accepted treatment of amblyopia involves forcing the patient to depend visually on the eye with diminished acuity and this is usually accomplished through occlusion therapy of the non-amblyopic eye. ${ }^{3}$

The visual system is thought to be sensitive to the effects of abnormal experience only dur- ing a limited period of time early in life when it is immature and plastic, and thus it is believed that occlusion therapy must be implemented between 6 months and 9 years of age in order to be effective. ${ }^{3}$ Improvement in visual acuity in young children is often dramatic after initiation of occlusion therapy of the non-amblyopic eye. However, there is conflicting evidence overall on the effectiveness of occlusion therapy for amblyopia. ${ }^{4}$ Standard clinical teaching is that occlusion therapy is ineffective in older children and adults. None the less, recent psychophysical studies have demonstrated significant neural plasticity in adult volunteers with and without amblyopia. ${ }^{5-7}$ In these instances the visual improvement was found to be specific to the orientation in which the volunteers were trained. In other words improvement in visual tasks was found to be specific for the retinal input. ${ }^{5-7}$

Pathological processes can affect the nonamblyopic eye at any time in life and it may become naturally occluded. A spate of recent case reports has indicated that some improvement in visual function occurs in adults in their amblyopic eye when their previously normal fellow eye has lost vision. ${ }^{8-10}$ A common disorder in the elderly in which severe and rapid central visual loss can occur is the neovascular form of age related macular degeneration (AMD). In this condition, which is often bilateral, development of disease is frequently asymmetrical in that one eye is affected earlier than the fellow eye. We have recently noted marked improvements in visual acuity in amblyopic eyes that were previously considered to have very poor vision following profound visual loss in the fellow eye as a result of choroidal neovascularisation. We therefore undertook to systemically screen for changes in visual acuity in the eye unaffected by choroidal neovascularisation in elderly patients who were participating in an ongoing longitudinal study on macular degenerative disease.

\section{Methods}

Records of 465 patients with AMD who were assessed at a specialist macular clinic of the Royal Victoria Hospital between 1989 and 1998 were scrutinised retrospectively. At this clinic all patients undergo standardised refraction and recording of best corrected distance and near acuity in both eyes. The optometrist is masked to the patients' clinical status. In addition, all patients undergo slit lamp biomicroscopy and stereoscopic evaluation of the macular retina of both eyes. One hundred and eighty nine patients had been seen on more than one occasion and had been subjected to the full clinical examination at each visit. 
Table 1 Laterality of amblyopic eyes showing refractive error if any

\begin{tabular}{lllc}
\hline No & Amblyopic eye & Refraction $(R)$ & Refraction $(L)$ \\
\hline 1 & Left & +5.5 & $+6.5 /-1.75$ at $75^{\circ}$ \\
2 & Right & 0.0 & 0.0 \\
3 & Left & +4.0 & -0.5 \\
4 & Right & -3.75 & $+1.0 /-0.75$ at $180^{\circ}$ \\
5 & Left & $+1.25 /-0.25$ at $70^{\circ}$ & 0.0 \\
6 & Left & $+1.75 /+0.5$ & -13.0 \\
7 & Left & +0.5 & -4.0 \\
8 & Left & $+8.00 /-2.0$ at $75^{\circ}$ & $+10.0 /-2.5$ at $90^{\circ}$ \\
9 & Right & -3.0 & -3.0 \\
\hline
\end{tabular}

We searched for cases where an improvement in either distance or near visual acuity of two or more lines was recorded in an eye when the other eye had choroidal neovascularisation. Twelve such cases were detected. In one case the patient had temporal arteritis and was taking systemic corticosteroids. Fluctuating vision was recorded in both eyes and thus this patient was not included. In nine of the remaining 11 cases, the eyes demonstrating an improvement in acuity had previously been diagnosed as amblyopic. Either this had been recorded by an ophthalmologist or the patients informed us that they had had a lazy eye since childhood. In the two other cases no history of amblyopia was recorded. Examination of the 189 patient records detected one additional case where a history of amblyopia had been recorded. In this case, both eyes had active choroidal neovascularisation and both eyes showed gradual deterioration in vision during the period of follow up. This patient is not included in the analysis.

ACUITY MEASUREMENTS

Distance acuity was measured using ETDRS charts on the $\log$ MAR $\left(\log _{10}\right.$ of the minimum angle of resolution) scale. ${ }^{11}$ The Snellen nomenclature for $\log$ MAR 0.0 is $6 / 6$ and that of $1.0 \log \mathrm{MAR}$ is $6 / 60$ with larger numbers signifying worse acuity. An increase of 0.1 logMAR indicates a worsening by one line and a decrease of $0.1 \log M A R$ reflects improvement by one line respectively on the ETDRS chart. Unlike Snellen charts there is a geometric progression in letter size with each line in the ETDRS charts. Letters in adjacent lines are 1.26 times larger than those of the line below and the change in terms of the visual angle subtended at a specified distance is linear.
Therefore a three line worsening anywhere on the chart represents a doubling of the visual angle.

Near acuity was measured using BaileyLovie near reading charts. This chart uses the $M$ notation with increasing numbers denoting increasing sizes of letters read and signifying worse acuity. A print size of $1 \mathrm{M}$ is equivalent to the Snellen notation of N8 and subtends an angle of 5 minutes at the requisite viewing distance. Similar to the distance acuity $\log$ MAR charts, the words in each subsequent line decrease in size according to the geometric principle of equal decrements of $0.1 \mathrm{log}$ units (1.26 times). ${ }^{11}$ An increase of three steps on the scale indicates a doubling of the visual angle.

\section{Results}

Of the nine patients who had a history of amblyopia, eight were female and one was male. The left eye was the amblyopic eye in six of the cases. The cause of amblyopia was anisometropia in seven and strabismus in two (Table 1). Apart from drusen, no significant macular pathology was detected in any of the amblyopic eyes. All cases were followed up for a minimum of 1 year (range 12-36 months with a mean of 18.6 months). The minimum number of visits was three and the maximum was six with a median of four. The change in distance visual acuity and near visual acuity in amblyopic (study eyes) and non-amblyopic (fellow eyes) over 36 months are shown in Tables 2-5.

\section{DISTANCE ACUITY}

Amblyopic study eyes

At presentation, the mean distance visual acuity in amblyopic eyes was 1.2 (SD 0.4) (Snellen equivalent: 6/95). By 6 months amblyopic eyes showed an improvement in acuity with the mean falling to $1.09 \log$ MAR (Snellen equivalent 6/75). By 12 months, an average improvement of three lines of acuity was found and this was maintained over the duration of the study. Two patients who were both followed for 18 months showed no change in distance acuity during the period of follow up. In the seven remaining patients all but one showed improvement in acuity within 12 months, and in one case the improvement in acuity only became noticeable after 18 months.

Table 2 Change in distance acuity in study eyes (amblyopic eyes) as number of lines from baseline at each visit (categorical intervals in months). Baseline distance acuity is given in $\log M A R$

\begin{tabular}{|c|c|c|c|c|c|c|}
\hline \multirow[b]{2}{*}{ Patient } & \multirow[b]{2}{*}{$\begin{array}{l}\text { Initial acuity } \\
\log M A R\end{array}$} & \multicolumn{5}{|c|}{ Change in distance acuity (number of lines) from baseline } \\
\hline & & $\begin{array}{l}\text { Visit } 1 \\
\text { (1-6 months) }\end{array}$ & $\begin{array}{l}\text { Visit } 2 \\
(7-12 \text { months })\end{array}$ & $\begin{array}{l}\text { Visit } 3 \\
(13-18 \text { months })\end{array}$ & $\begin{array}{l}\text { Visit } 4 \\
\text { (19-24 months) }\end{array}$ & $\begin{array}{l}\text { Visit } 5 \\
\text { (25-30 months) }\end{array}$ \\
\hline 1 & 1.2 & 0 & & -2 & & \\
\hline 2 & 0.9 & 0 & 0 & 0 & & \\
\hline 3 & 0.9 & -1 & -3 & -2 & -2 & \\
\hline 4 & 1.6 & -6 & -10 & -10 & -10 & -10 \\
\hline 5 & 1.6 & -1 & -6 & -6 & -6 & \\
\hline 6 & 1.6 & 0 & 0 & 0 & -3 & -3 \\
\hline 7 & 1.2 & -4 & -4 & & & \\
\hline 8 & 1.5 & -1 & -3 & -3 & & \\
\hline 9 & 0.6 & 0 & 0 & 0 & & \\
\hline Average & 1.2 & -1.4 & -3.3 & -2.9 & -5.3 & -6.5 \\
\hline SD & 0.4 & 2.1 & 3.5 & 3.5 & 3.6 & 4.9 \\
\hline Min & 0.6 & -6 & -10 & -10 & -10 & -10 \\
\hline Max & 1.6 & 0 & 0 & 0 & -2 & -3 \\
\hline
\end{tabular}


Table 3 Change in distance acuity in fellow eyes as number of lines from baseline at each visit (categorical intervals in months). Baseline distance acuity is given in $\log M A R$

\begin{tabular}{|c|c|c|c|c|c|c|}
\hline \multirow[b]{2}{*}{ Patient } & \multirow[b]{2}{*}{$\begin{array}{l}\text { Initial acuity } \\
\log M A R\end{array}$} & \multicolumn{5}{|c|}{ Change in distance acuity (number of lines) from baseline } \\
\hline & & $\begin{array}{l}\text { Visit } 1 \\
\text { (1-6 months) }\end{array}$ & $\begin{array}{l}\text { Visit } 2 \\
(7-12 \text { months })\end{array}$ & $\begin{array}{l}\text { Visit } 3 \\
\text { (13-18 months) }\end{array}$ & $\begin{array}{l}\text { Visit } 4 \\
\text { (19-24 months) }\end{array}$ & $\begin{array}{l}\text { Visit } 5 \\
(25-30 \text { months) }\end{array}$ \\
\hline 1 & 0.4 & -1 & & 6 & & \\
\hline 2 & 0.4 & 0 & 3 & 3 & & \\
\hline 3 & 0.6 & 0 & 10 & 9 & 10 & \\
\hline 4 & 1 & 3 & 3 & 0 & 0 & 0 \\
\hline 5 & 1 & 3 & & 3 & 3 & \\
\hline 6 & 0.5 & 1 & 1 & 11 & 11 & 11 \\
\hline 7 & 1.2 & 0 & 4 & & & \\
\hline 8 & 0.8 & 0 & 0 & 0 & & \\
\hline 9 & 0.6 & 8 & 7 & 10 & & \\
\hline Average & 0.7 & 1.6 & 4.0 & 5.3 & 6.0 & 5.5 \\
\hline SD & 0.3 & 2.7 & 3.5 & 4.4 & 5.4 & 7.8 \\
\hline Min & 0.4 & -1 & 0 & 0 & 0 & 0 \\
\hline Max & 1.2 & 8 & 10 & 11 & 11 & 11 \\
\hline
\end{tabular}

Non-amblyopic fellow eyes

At presentation, the mean distance visual acuity of the non-amblyopic fellow eyes was 0.7 (0.3) (6/30). By 12 months, an average of 4.0 lines of acuity was lost. By the final visit, three patients suffered losses of acuity in excess of six lines which is a quadrupling of the visual angle. Only one eye showed no change in distance acuity from baseline during the period of follow up.

NEAR ACUITY

Amblyopic study eyes

At initial presentation, mean near visual acuity was $6.7 \mathrm{M}(\mathrm{N} 48)$. An improvement of approximately two lines was noted by 12 months increasing to 2.6 lines by 24 months.
Non-amblyopic fellow eyes

At initial presentation, the mean near visual acuity was 3.1M (N24). By 12 months, fellow eyes showed a deterioration of five lines of near acuity which remained unchanged thereafter. Only one of the nine eyes showed no deterioration in near acuity.

Figure 1 illustrates the mean change in distance visual acuity and near visual acuity respectively over time.

PATIENTS WITHOUT A HISTORY OF AMBLYOPIA Two cases with no history of amblyopia were recorded as having an improvement in acuity. One case showed a two line improvement in distance acuity on the second visit from baseline and no change in near acuity. The

Table 4 Change in near acuity in study eyes (amblyopic eyes) as number of lines from baseline at each visit (categorical intervals in months). Baseline near acuity is given in $M$ notation

\begin{tabular}{|c|c|c|c|c|c|c|}
\hline \multirow[b]{2}{*}{ Patient } & \multirow[b]{2}{*}{$\begin{array}{l}\text { Near acuity } \\
\text { (months) }\end{array}$} & \multicolumn{5}{|c|}{ Change in near acuity (number of lines) from baseline } \\
\hline & & $\begin{array}{l}\text { Visit } 1 \\
\text { (1-6 months) }\end{array}$ & $\begin{array}{l}\text { Visit } 2 \\
\text { (7-12 months) }\end{array}$ & $\begin{array}{l}\text { Visit } 3 \\
\text { (13-18 months) }\end{array}$ & $\begin{array}{l}\text { Visit } 4 \\
(19-24 \text { months })\end{array}$ & $\begin{array}{l}\text { Visit } 5 \\
\text { (25-30 months) }\end{array}$ \\
\hline 1 & 10 & 0 & & -5 & & \\
\hline 2 & 1.6 & -2 & -1 & -1 & & \\
\hline 3 & 1 & 0 & 0 & 1 & 1 & \\
\hline 4 & 4 & -1 & -2 & -6 & -6 & -6 \\
\hline 5 & 12 & 0 & -2 & -2 & -3 & \\
\hline 6 & 12 & 0 & 0 & 0 & $\star$ & -2 \\
\hline 7 & 12 & -6 & -7 & & & \\
\hline 8 & 6.3 & -1 & -2 & & & \\
\hline 9 & 1.6 & -1 & -1 & 0 & & \\
\hline Average & 6.7 & -1.2 & -1.9 & -1.9 & -2.7 & -4.0 \\
\hline SD & 4.8 & 1.9 & 2.2 & 2.7 & 3.5 & 2.8 \\
\hline $\operatorname{Min}$ & 1 & -6 & -7 & -6 & -6 & -6 \\
\hline $\operatorname{Max}$ & 12 & 0 & 0 & 1 & 1 & -2 \\
\hline
\end{tabular}

^Indicates missing near acuity reading. The change in near acuity was therefore not available for the study eye of patient 6 on the fourth follow up visit.

Table 5 Change in near acuity in fellow eyes as number of lines from baseline at each visit (categorical intervals in months). Baseline near acuity is given in $M$ notation

\begin{tabular}{|c|c|c|c|c|c|c|}
\hline \multirow[b]{2}{*}{ Patient } & \multirow[b]{2}{*}{$\begin{array}{l}\text { Near acuity } \\
\text { (months) }\end{array}$} & \multicolumn{5}{|c|}{ Change in near acuity (number of lines) from baseline } \\
\hline & & $\begin{array}{l}\text { Visit } 1 \\
\text { (1-6 months) }\end{array}$ & $\begin{array}{l}\text { Visit } 2 \\
\text { (7-12 months) }\end{array}$ & $\begin{array}{l}\text { Visit } 3 \\
\text { (13-18 months) }\end{array}$ & $\begin{array}{l}\text { Visit } 4 \\
\text { (19-24 months) }\end{array}$ & $\begin{array}{l}\text { Visit } 5 \\
\text { (25-30 months) }\end{array}$ \\
\hline 1 & 2 & 1 & & 7 & & \\
\hline 2 & 1 & 0 & 7 & 2 & & \\
\hline 3 & 1.6 & 3 & 8 & 8 & 8 & \\
\hline 4 & 4 & 2 & 1 & 2 & 2 & 2 \\
\hline 5 & 6.3 & 1 & 2 & 2 & 2 & \\
\hline 6 & 3 & 1 & 1 & 7 & 7 & 7 \\
\hline 7 & 8 & 0 & 0 & & & \\
\hline 8 & 1.2 & 0 & 9 & & & \\
\hline 9 & 1.2 & 9 & 9 & 9 & & \\
\hline Average & 3.1 & 1.9 & 4.6 & 5.3 & 4.8 & 4.5 \\
\hline SD & 2.5 & 2.8 & 4.0 & 3.1 & 3.2 & 3.5 \\
\hline Min & 1 & 0 & 0 & 2 & 2 & 2 \\
\hline Max & 8 & 9 & 9 & 9 & 8 & 7 \\
\hline
\end{tabular}



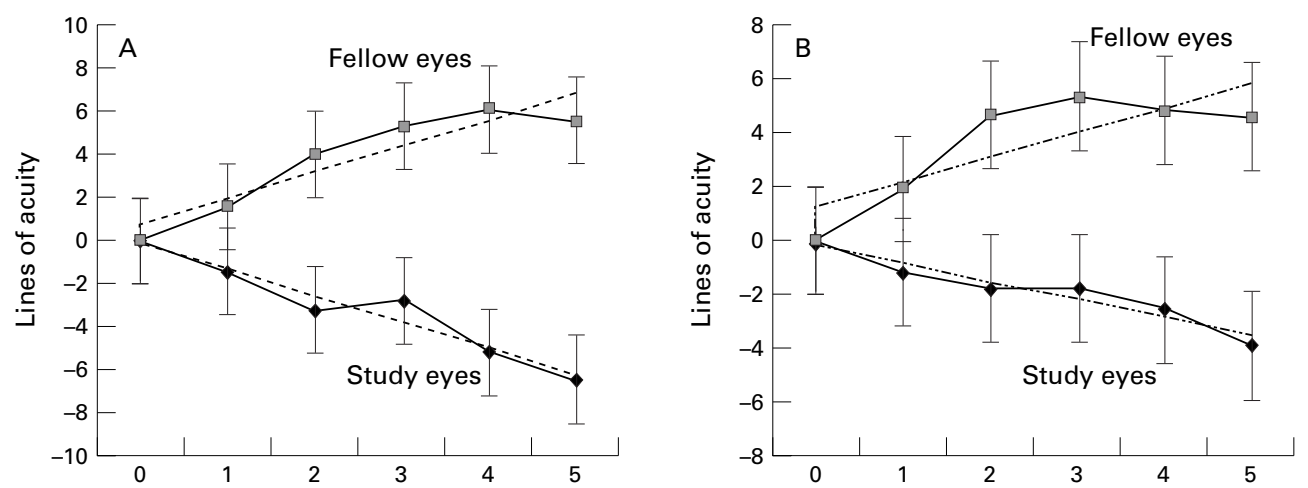

Figure 1 Mean change in distance acuity $(A)$ and near acuity (B) for study eyes and fellow eyes for each visit. Error bars indicate standard deviation of the mean and broken lines show the trend over time. The $x$ axis shows the visit number and the $y$ axis shows lines of acuity (positive numbers indicate worsening vision and negative numbers improving vision).

other case showed a three line improvement in distance acuity accompanied by a one line improvement in near acuity which occurred between baseline and the 6 month follow up visit. No further change in acuity occurred in these cases with continuing follow up. Both cases had bilateral AMD. The improvement in both cases occurred in the first eye to suffer visual loss after the second eye had developed overt disease.

\section{Discussion}

There is accumulating evidence to show that neural plasticity exists in adults and that repetitive practice can improve performance on a variety of visual tasks in adult humans with normal visual capacities. ${ }^{6}$ More recently, evidence has accrued to show that adult amblyopes also demonstrate substantial and significant perceptual learning of vernier acuity tasks and that this learning reflects alterations in early neural processes. ${ }^{57}$ In these cases the improvement was task and orientation specific suggesting that it was due to sharpening of early neural responses localised beyond the site of convergence of the two eyes.

The present study has shown that an amblyopic eye can recover a level of visual function even in older individuals when the previously normal fellow eye is lost to disease. Although the improvement in many cases did not result in complete reversal of amblyopia with the mean distance acuity improving from a baseline of $1.2 \log$ MAR to $0.87 \log$ MAR at 12 months, this suggests that the amblyopic eye has a functional reserve that is only implemented when the fellow eye undergoes a significant deterioration in vision. It is generally believed that if amblyopic eyes are not treated early any chance of visual improvement will be lost. The visual potential of amblyopic eyes is often disregarded. For example, in the event of a cataract developing in an amblyopic eye, treatment may be withheld.

Age related macular degeneration causes a rapid deterioration in visual acuity of the "good eye" and essentially acts as a form of occlusion therapy. Patients are then forced to use their hitherto lazy eye. It is interesting that the results of Levi et al, whose studies were conducted entirely under stringent laboratory conditions, demonstrate that amblyopic eyes that are trained using stimuli at specific orientations show improvement in that orientation only. ${ }^{7}$ By contrast, the present study with patients from a clinical setting has shown that a global improvement in visual function can occur, which is detectable using standard measures of visual function.

In the present study, we only observed an improvement of two or more lines of distance or near acuity in one eye of 12 of 189 patients whose case records were scrutinised. It was noteworthy that nine of these 12 patients had a history of amblyopia. In the two eyes where an improvement in acuity was noted without a history of amblyopia, no obvious cause was found to explain this change. In these two cases, improvement was limited to two lines and three lines of distance acuity respectively. This was in contrast with amblyopic eyes where much larger sustained improvement in distance and near acuity was noted in follow up visits.

It was interesting that of the 10 patients identified as having amblyopia, all but one had AMD in the eye without amblyopia. This may reflect the referral patterns as individuals who develop AMD in an amblyopic eye are highly unlikely to notice the visual loss and seek help. However, there is a possibility that the amblyopic eye may be protected from AMD. The present study was not designed to obtain estimates of the prevalence of amblyopia in older people. Furthermore, as it was retrospective it was not possible to identify factors which could potentially influence recovery from amblyopia. Longitudinal studies of the natural history of visual change in AMD on large numbers of people will be needed to answer these questions.

A chance observation of marked improvement of vision in an amblyopic eye of a case with AMD in the fellow eye prompted this study. Despite the limitations of the present study we feel we have obtained evidence to show that visual function in eyes with amblyopia improves substantially when the fellow eye become visually impaired and that age is not a barrier to this. In amblyopic eyes improvement in distance acuity appeared to precede corresponding improvements in near acuity and this pattern was occasionally the reverse. Most of the improvement occurred within 12 months 
from initial presentation but in one case the improvement was not documented until the 24 month visit. Clearly, these findings have important implications in terms of management and rehabilitation of patients who have a history of amblyopia. Furthermore, these findings provide additional incentive to clinicians to manage co-morbidity in the amblyopic eyes of patients more proactively.

1 Greenwald MJ, Parks MM. Amblyopia. In: Duane TD, ed. Clinical ophthalmology. Hagerstown, MD: Harper and Row, Clinical ophthalmology.

2 Campos E. Amblyopia. Surv Ophthalmol 1995;40:23-39.

Parks MM. Treatment of the sensorial adaptations and amblyopia. In: Duane TD, ed. Clinical ophthalmology. Hagerstown, MD: Harper and Row, 1989:vol 1,11:1-14.
4 Moseley MJ, Fielder AR, Irwin M, et al. Effectiveness of occlusion therapy in ametropic amblyopia; a pilot study. $\mathrm{Br}$ occlusion therapy in ametropic

5 Levi DM, Polat U. Neural plasticitiy in adults with amblyopia. Proc Natl Acad Sci USA 1996;93:6830-4.

6 Karni A, Sagi D. Where practice makes perfect in texture discrimination: evidence for primary visual cortex plasticity. Proc Natl Acad Sci USA 1991;88:4966-70.

7 Levi DM, Polat U, Hu YS. Improvement in vernier acuity in dults with amblyopia: practice makes better. Invest Ophthalmol 1997;38:1493-507.

8 Simmers AJ, Gray LS. Improvement of visual function in an adult amblyope. Optom Vis Sci 1999;76:82-7.

9 Wilson ME. Adult amblyopia reversed by contralateral cataract formation. I Pediat Ophthalmol Strabismus 1992;29: ract form $100-2$.

10 Kushner BJ, Morton GV. Postoperatve binocularity in adults with longstanding strabismus. Ophthalmology 1992; 99:316-19.

11 Johnston AW. Making sense of the $\mathrm{M}, \mathrm{N}$ and $\log$ MAR systems of specifying visual acuity. Problems in Optometry 1991;3:394-407. 